\title{
Efektivitas Waktu Persilangan Tiga Genotipe Cabai (Capcicum sp) pada Persilangan Dialel
}

\author{
Effectiveness of Crossing Time of Three Chili (Capcicum sp) Genotypes in Dialel Crosses
}

\section{Retno D. Andayani*, Navita Maharani}

Program Studi Agroteknologi, Fakultas Pertanian, Universitas Islam Kadiri, Jl. Sersan Suharmaji No 38, Manisrenggo, Kota Kediri 64128, Indonesia

*E-mail Penulis Korespondensi: retnodwiandayani@yahoo.co.id

\begin{abstract}
Chili is an important horticultural commodity in Indonesia. However, its production is still not optimal because there are not many superior seeds available, which causes low productivity. One solution to this problem is to improve planting material (seeds) by a plant breeding program through a hybridization process. Crossing different types of chili requires the right time to increase the chances of success. The purpose of this study was to determine the effectiveness of crossing three genotypes of chili (two introduced and one local). The study was carried out with a factorial randomized design. The first factor was a combination of crosses of three parents, namely Sweet Italian, Garda and Katokkon by dialel crosses. The second factor was the time of crossing, namely at 04.00, 05.00, 06.00, 07.00, 08.00. The results of the analysis showed that the combination of parents had an interaction with crossing time in increasing the dsuccess of the crosses. Each parent combination hah a specific time for crossing. If the female parent was Sweet Italian, the time of crossing early in the morning (low temperature) was more optimal, which was between 04.00-07.00. For Katokkon $\times$ Garda crosses and their reciprocals, the percentage of successful crosses increased if it was done at 06.00-08.00. None of the crosses between Garda $\times$ Sweet Italian were successful or were entirely lethal.
\end{abstract}

Keywords: chili, crossing time, dialele, introduction genotype

\section{ABSTRAK}

Cabai merupakan komoditas hortikultura yang penting di Indonesia. Namun produksinya masih belum optimal karena belum banyak tersedia benih unggul, yang menyebabkan rendahnya produktivitas. Salah satu solusi masalah tersebut adalah dengan perbaikan bahan tanam (benih) melalui program pemuliaan tanaman dengan proses persilangan (hibridisasi). Persilangan cabai yang berbeda jenis memerlukan waktu yang tepat untuk dapat meningkatkan peluang keberhasilannya. Tujuan penelitian ini adalah untuk mengetahui efektivitas waktu persilangan tiga genotipe cabai (dua introduksi dan satu lokal). Penelitian dilaksanakan dengan rancangan acak kelompok faktorial, Faktor pertama adalah kombinasi persilangan dari tiga tetua, yaitu Sweet Italian, Garda dan Katokkon secara dialel. Faktor kedua adalah waktu persilangan, yaitu pada pukul 04.00, 05.00, 06.00, 07.00, 08.00. Hasil analisis menunjukkan bahwa kombinasi tetua memiliki interaksi dengan waktu persilangan dalam meningkatkan keberhasilan persilangan. Tiap kombinasi tetua memiliki waktu yang spesifik untuk persilangan. Jika tetua betina Sweet Italian, waktu persilangannya semakin pagi (suhu rendah) semakin optimal, yakni di antara pukul 04.00-07.00. Untuk persilangan Katokkon $\times$ Garda maupun resiproknya, persentase keberhasilan persilangan semakin meningkat jika dilakukan pada pukul 06.00-08.00. Tidak ada penyerbukan silang antara Garda×Sweet Italian yang berhasil persilangan atau seluruhnya letal.

Kata kunci: cabai, dialel, genotipe introduksi, waktu persilangan

\section{PENDAHULUAN}

Cabai (Capsicum sp.), yang termasuk tanaman hortikultura kelompok sayuran buah, merupakan komoditas hortikultura unggulan nasional. Berdasarkan data Badan Pusat Statistik (2009), total areal pertanaman sayuran di Indonesia sebesar 990,915 ha dan $20,46 \%$ dari total lahan ditanamai komoditas cabai. Meskipun demikian, rata-rata produktivitas cabai di Indonesia pada tahun 2008 baru mencapai 5,36 ton per ha, sedangkan menurut Bahar dan Nugrahaeni (2008) potensi hasil cabai yang dapat dicapai 17-21 ton per ha.

Badan Pusat Statistik (2013) mencatat dari tahun 2007 samapai 2011 terjadi penurunan tingkat produktivitas tanaman cabai, yaitu secara berturut-turut sebesar 7,6; 6,14; 5,28; 5,15; dan 5,02 ton per ha. Penurunan produktivitas disebabkan beberapa kendala, seperti sulitnya memperoleh varietas cabai berdaya hasil tinggi serta rendahnya kualitas cabai yang dihasilkan. Kondisi cuaca yang tidak dapat diprediksi turut serta memperburuk kualitas cabai yang dihasilkan. Kombinasi kedua masalah tersebut menyebabkan fenomena tingginya harga cabai pada beberapa tahun terakhir. Salah satu cara yang dilakukan untuk mengatasi masalah tersebut adalah dengan perbaikan varietas melalui program pemuliaan tanaman. 
Benih unggul diperoleh melalui kegiatan pemuliaan tanaman yang bertujuan untuk mengembangkan varietas yang lebih unggul daripada varietas yang telah ada dari karakter daya hasil dan kualitas. Benih yang unggul adalah benih yang mampu berproduktivitas tinggi dan menghasilkan kualitas buah yang baik. Kegiatan pemuliaan tanaman pada tanaman cabai diawali dengan meningkatkan keragaman genetiknya. Peningkatan keragaman genetik dapat dilakukan dengan melakukan persilangan pada jenis yang sudah ada, atau mendatangkan bahan genetik dari pusal asalnya (center of origin). Menurut Vavilov (1992), center of origin tanaman cabai adalah Amerika Tengah, sehingga keragaman jenis cabai di Amerika Tengah cenderung lebih tinggi dibandingkan dengan di Indonesia. Keragaman jenis inilah yang digunakan sebagai bahan untuk mendapatkan keragaman genetik untuk pemuliaan tanaman.

Keragaman genetik dapat diperluas dengan cara hibridisasi (persilangan). Persilangan digunakan untuk memperoleh karakter yang diinginkan oleh peneliti dengan cara menggabungkan sifat pada dua tetua atau lebih yang memiliki sifat unggul yang diinginkan. Dalam persilangan tanaman cabai diketahui adanya fenomena heterosis, yaitu hibrida F1 yang dihasilkan memperlihatkan penampilan yang lebih baik daripada rata-rata kedua tetuanya (Sujiprihati $e t$ al., 2007). Heterobeltiosis adalah hibrida F1 yang dihasilkan memperlihatkan penampilan yang lebih baik daripada penampilan salah satu tetua terbaik. Hal ini memungkinkan untuk dibentuk varietas hibrida yang memiliki sifat lebih baik daripada varietas tanaman menyerbuk sendiri. Sifat-sifat tersebut antara lain meliputi daya hasil, resistensi terhadap hama dan penyakit, dan kualitas buah.

Peningkatan kualitas buah cabai dapat dicapai melalui proses hibridisasi dengan cara memilih tetua yang memiliki daging buah tebal dan berdaya simpan panjang. Lamanya daya simpan cabai bergantung kepada ketebalan kulit cabai. Kulit yang semakin tebal cenderung lebih mampu menahan serangan hama, memar pada saat pengangkutan, dan juga lebih tahan terhadap busuk.

Banyak penelitian tentang heterosis dan heterobeltiosis pada cabai telah dilaksanakan sebelumnya (Nasir, 1999; Herison et al., 2001; Sousa dan Maluf, 2003; Seneviratne dan Kannangara, 2004; Geleta et a.,. 2006; Sujiprihati et al., 2007; Zou et al 2007; Kirana dan Sofiari, 2007; Kamble et al., 2009; Marame et al. 2009). Beberapa penelitian tersebut mendapatkan bahwa hasil yang tinggi dapat dicapai jika turunan dari kombinasi persilangan tersebut memiliki heterosis positif.

Penelitian ini menggunakan tiga genotipe tetua cabai dengan metode persilangan dialel penuh. Masing-masing tetua memiliki keunggulannya, sehingga diharapkan mampu menghasilkan turunan (F1) yang memiliki gabungan sifat berdaya hasil tinggi dan memiliki kualitas buah yang baik, seperti berdaging tebal, berwarna merah cerah dan memiliki kadar capsaicin yang tinggi. Juga diharapkan hasil dari persilangan memiliki nilai heterosis yang positif.

\section{BAHAN DAN METODE}

\section{Waktu dan Tempat}

Penelitian ini dilaksanakan pada Maret-September 2018 di Desa Cendono, Kecamatan Kandat, Kabupaten Kediri dan Laboratorium Agroteknologi Fakultas Pertanian, Universitas Islam Kadiri (UNISKA). Uji organoleptik dilakukan di area kampus Universitas Islam Kadiri dan di beberapa pasar tradisional di kawasan Kota dan Kabupaten Kediri.

\section{Bahan dan Alat}

Benih introduksi yang digunakan adalah Sweet Italian dan Garda, sementara benih lokal adalah Katokkon. Media tanam yang digunakan adalah media tanam jadi yang kemudian diperkaya dengan menambahkan kompos dan sekam bakar, pupuk dasar (pupuk kandang kambing), pupuk tambahan (NPK Mutiara 16:16:16) dan pestisida Furadan, Antracol, Curacron dan Demolish.

Alat-alat yang digunakan dalam penelitian ini adalah alat-alat persemaian dan pembibitan, alat-alat persilangan, naungan, alat standar pengamatan, alat dokumentasi dan alat standar budidaya tanaman.

\section{Metode}

Metode yang digunakan dalam penelitian ini adalah eksperimental dengan menggunakan rancangan acak kelompok faktorial dengan 3 ulangan. Faktor pertama adalah kombinasi persilangan dialel dari 3 tetua cabai dan faktor kedua adalah waktu persilangan, yaitu pukul 04.00, 05.00, 06.00, 07.00 dan 08.00.

Persilangan dengan penyerbukan silang buatan dilakukan ketika tetua sudah berbunga minimal $50 \%$ dan dilakukan pada pukul 04.00; 05.00; 06.00; 07.00 dan 08.00, sesuai perlakuan. Persilangan dimulai dengan melakukan emaskulasi dan panen benang sari. Serbuk sari kemudian disapukan ke putik tetua yang diinginkan. Bunga yang telah disilangkan, disungkup untuk melindungi dari serangga dan diberikan label nama tetua dan waktu persilangan. Tanda apakah persilangan itu berhasil atau tidak dapat dilihat 2 hari setelah persilangan. Bunga yang tidak rontok dan pada pangkal bunga masih segar, menandakan bahwa persilangan itu berhasil. Sedangkan bunga yang rontok atau pangkal bunga layu dan mulai menguning, menandakan persilangan tersebut gagal. 
Data yang didapat, dianalisis dengan menggunakan analisis ragam (Anova), jika terdapat ada pengaruh yang nyata, maka akan dilanjutkan dengan uji BNT pada tingkat 0,05 .

\section{HASIL DAN PEMBAHASAN}

Keberhasilan hasil persilangan dapat dilihat dari persentase hasil persilangan yang berhasil dilakukan. Data persilangan (Gambar 1) menunjukkan pola bahwa setiap kombinasi persilangan memiliki waktu persilangan yang berbeda.

Kombinasi persilangan Sweet Italian $\times$ Katokkon menunjukkan bahwa waktu persilangan yang paling optimal adalah pada pukul 06.00 dengan keberhasilan sebesar 79,17\% (Tabel 1). Terjadi peningkatan sampai pukul 06.00 dan kemudian menurun sampai pukul 08.00. Hal ini didukung dengan hasil uji perbandingan BNT yang dilakukan (Table 1). Dengan demikian, sesuai dengan yang ditunjukkan oleh grafik, hasil terbaik persilangan ada pada waktu 06.00 pagi.

Cukup rendahnya keberhasilan persilangan dapat mengindikasikan beberapa sebab, seperti terdapat inkompatibitas antara putik Sweet Italian dan benang sari Katokkon, atau bisa juga disebabkan karena tidak sesuainya kondisi cuaca bagi penyerbukan atau pembuahan. Diketahui bahwa Sweet Italian merupakan cabai introduksi yang berasal dari Amerika Selatan (Bolivia) yang beriklim sub tropis. Sehingga kemungkinan mengalami beberapa kendala dalam beradaptasi di lingkungan tropis. Kombinasi persilangan ini sepertinya menginginkan suhu yang lebih dingin agar keberhasilan persilangan menjadi lebih tinggi.

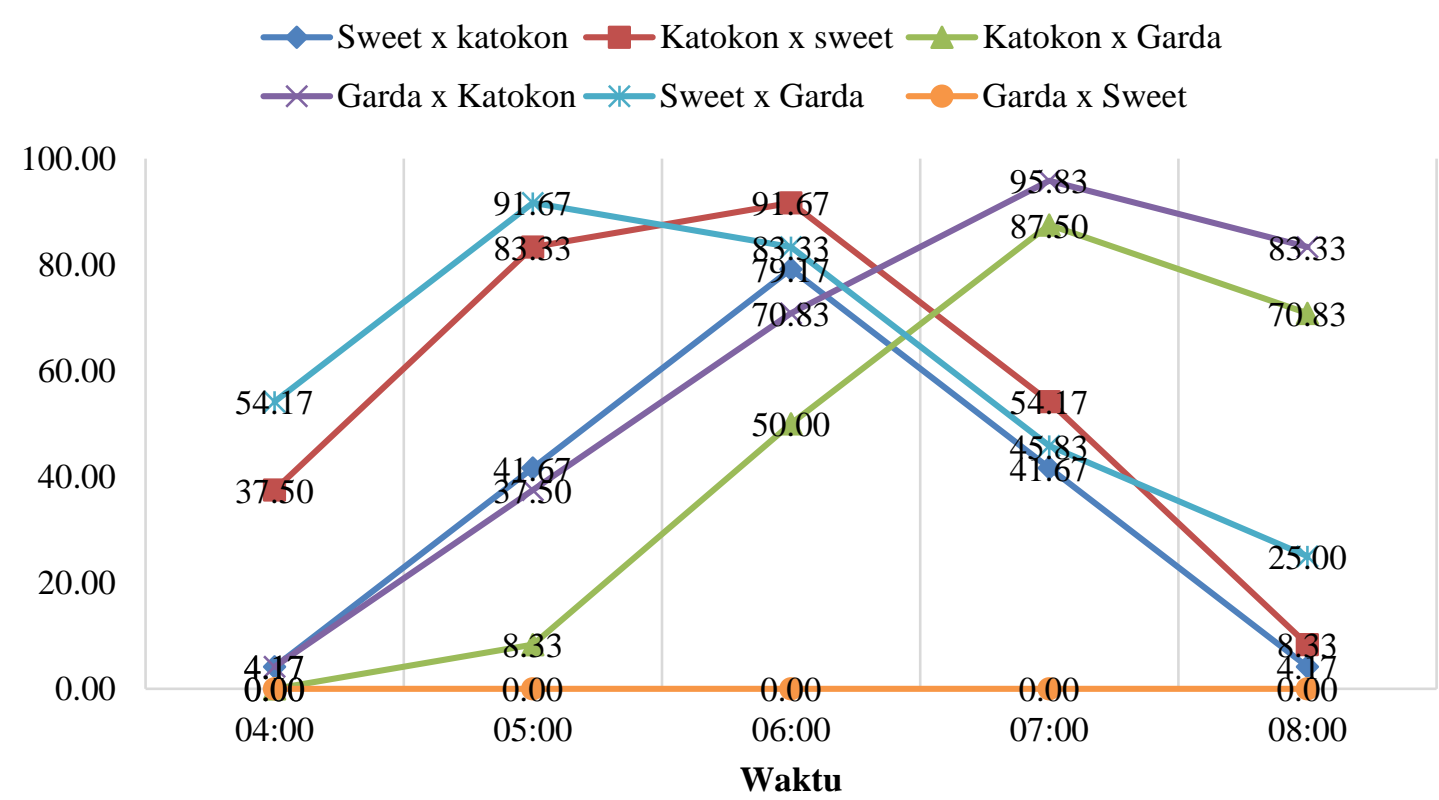

Gambar 1. Grafik persentase keberhasilan persilangan

Tabel 1. Rata-rata persilangan Sweet Italian $\times$ Katokkon dan resiproknya

\begin{tabular}{lccc}
\hline Persilangan & Waktu & Rata-rata & Notasi \\
\hline Sweet Italian $\times$ Katokkon & 04.00 & 4,17 & ab \\
& 05.00 & 41,67 & abcde \\
& 06.00 & 79,17 & def \\
& 07.00 & 41,67 & abcde \\
& 08.00 & 4,17 & ab \\
\hline \multirow{2}{*}{ Katokkon $\times$ Sweet Italian } & 04.00 & 37,5 & abcd \\
& 05.00 & 83,33 & def \\
& 06.00 & 91,67 & ef \\
& 07.00 & 54,17 & bcdef \\
\hline
\end{tabular}

Keterangan: Nilai rata-rata yang diikuti dengan huruf notasi yang sama tidak berbeda nyata berdasarkan Uji BNJ 0,05 
Kombinasi persilangan Katokkon $\times$ Sweet Italian menunjukkan bahwa waktu persilangan yang paling optimal adalah pada pukul 06.00, dengan keberhasilan sebesar 91,67\%. Pola ini mulai meningkat mulai pukul 05.00 (83,33\%) dan kemudian mulai menurun pada pukul 07.00. Hal ini tenyata tidak sesuai dengan hasil uji perbandingan BNT yang dilakukan (Table 1). Jika pada grafik, waktu yang baik untuk melakukan persilangan Katokkon $\times$ Sweet Italian adalah pada pukul 05.00 sampai pukul 06.00, maka menurut hasil uji BNT, rentang waktu terbaik adalah pada pukul 05.00 sampai pukul 07.00.

Adanya pengaruh tetua betina pada pewarisan suatu karakter akan menyebabkan keturunan persilangan resiproknya memberikan hasil yang berbeda, dimana ciri tetua betina akan lebih dominan tampak pada keturunannya (Ritonga, 2013). Hal ini menyebabkan tidak dapat digabungkannya analisis pewarisan sifat F1 dan F1R karena akan menghasilkan segregasi F2 berbeda dan tidak sesuai dengan segregasi Mendel. Arif et al. (2012) juga melaporkan bahwa tidak terdapat pengaruh tetua betina pada pewarisan karakter umur berbunga, umur berbunga, dan bobot per buah tanaman cabai. Tingginya hasil persentase persilangan, mengindikasikan bahwa kedua jenis cabai ini cocok untuk disilangkan dengan syarat Katokkon dijadikan tetua betina dan Sweet Italian dijadikan tetua jantan.

Kombinasi persilangan Katokkon $\times$ Garda menunjukkan bahwa waktu persilangan yang paling optimal adalah pada pukul 06.00, dengan keberhasilan sebesar 91,67\%. Pola ini mulai meningkat mulai pukul 05.00 (83,33\%) dan kemudian mulai menurun pada pukul 07.00. Hal ini ternyata tidak sesuai dengan hasil uji perbandingan BNT yang dilakukan (Tabel 2). Jika pada grafik, waktu yang baik untuk melakukan persilangan Katokkon $\times$ Garda pada pukul 07.00 sampai pukul 08.00, maka menurut hasil uji, rentang waktu terbaik adalah pada pukul 06.00 sampai pukul 08.00. Tingginya hasil persentase persilangan, mengindikasikan bahwa kedua jenis cabai ini cocok untuk disilangkan. Namun perlu dilakukan upaya adaptasi dan penyesuaian kondisi cuaca agar mampu menekan kerontokan bunga.

Kombinasi persilangan Garda×Katokkon menunjukkan bahwa waktu keberhasilan persilangan adalah pada pukul 06.00, kemudian yang paling optimal adalah pada pukul 07.00 dan mulai menurun pada pukul 08.00. Hal ini didukung dengan hasil uji perbandingan BNT yang dilakukan (Tabel 2). Sama dengan yang ditunjukkan oleh grafik, hasil terbaik persilangan ada pada rentang waktu 06.00 sampai 08.00 pagi.

Tabel 2. Rata-rata persilangan Katokkon $\times$ Garda dan resiproknya

\begin{tabular}{|c|c|c|c|}
\hline Persilangan & Waktu & Rata-rata & Notasi \\
\hline \multirow{5}{*}{ Katokkon $\times$ Garda } & 04.00 & 0,00 & $\mathrm{a}$ \\
\hline & 05.00 & 8,33 & $a b$ \\
\hline & 06.00 & 50,00 & abcdef \\
\hline & 07.00 & 87,5 & def \\
\hline & 08.00 & 70,83 & cdef \\
\hline \multirow{5}{*}{ Garda $\times$ Katokkon } & 04.00 & 4,17 & $a b$ \\
\hline & 05.00 & 37,5 & abcd \\
\hline & 06.00 & 70,83 & cdef \\
\hline & 07.00 & 95,83 & $\mathrm{f}$ \\
\hline & 08.00 & 83,33 & def \\
\hline
\end{tabular}

Keterangan: Nilai rata-rata yang diikuti dengan huruf notasi yang sama tidak berbeda nyata berdasarkan Uji BNJ 0,05

Rata-rata waktu persilangan Garda×Katokkon maupun resiproknya, menunjukkan bahwa kedua varietas ini memiliki waktu masak polen dan putik yang hampir sama, yaitu direntang waktu 06.00 sampai 08.00 (Tabel 2). Hal ini sangat mempengaruhi hasil persilangan, semakin bersamaan waktu masak polen dan putik, keberhasilan persilangan yang dilakukan juga semakin tinggi.

Kombinasi persilangan Sweet Italian $\times$ Garda menunjukkan bahwa waktu persilangan yang paling optimal adalah pada pukul 05.00. Pola ini mulai menurun pada pukul 06.00. Hal ini tenyata tidak sesuai dengan hasil uji perbandingan BNT yang dilakukan (Tabel 3). Menurut hasil uji, rentang waktu terbaik untuk melakukan persilangan adalah pada pukul 04.00 sampai pukul 07.00.

Sama seperti persilangan Sweet Italian $\times$ Katokkon, persilangan Sweet Italian $\times$ Garda juga menginginkan suhu yang lebih dingin agar persentase persilangan menjadi lebih tinggi. Hal ini mungkin menyesuaikan dengan asal tetua Sweet Italian yang berasal dari wilayah subtropis. Sehingga semakin dingin suhu, persentase persilangan juga semakin meningkat. Kombinasi persilangan dengan pola seperti ini adalah hanya terjadi jika Sweet Italian sebagai tetua betina.

Seluruh kombinasi persilangan Garda $\times$ Sweet Italian tidak ada yang berhasil disilangkan. Bunga yang silangkan selalu mengalami layu dan busuk. Hal ini diduga ada ketidaksesuaian atau inkompatibitas antara putik varietas Garda dan benang sari varietas Sweet Italian. Hal ini lazim terjadi dengan berbagai kemungkinan penyebab, seperti waktu matang putik dan benang sari yang tidak sama, putik dan benang sari memiliki struktur yang tidak sama, bisa juga akibat adanya maternal effect. 
Tabel 3. Rata-rata persilangan Sweet Italian×Garda dan resiproknya

\begin{tabular}{cccc}
\hline Persilangan & Waktu & Rata-rata & Notasi \\
\hline \multirow{4}{*}{ Sweet Italian $\times$ Garda } & 04.00 & 54,17 & bcdef \\
& 05.00 & 91,67 & ef \\
& 06.00 & 83,33 & def \\
& 07.00 & 45,83 & abcdef \\
& 08.00 & 25,00 & abc \\
\hline \multirow{5}{*}{ Garda×Sweet Italian } & 04.00 & 0 & $\mathrm{a}$ \\
& 05.00 & 0 & $\mathrm{a}$ \\
& 06.00 & 0 & $\mathrm{a}$ \\
& 07.00 & 0 & $\mathrm{a}$ \\
\hline
\end{tabular}

Keterangan: Nilai rata-rata yang diikuti dengan huruf notasi yang sama tidak berbeda nyata berdasarkan Uji BNJ 0,05

Menurut Emboden (1964) yang diulas dalam Ritonga (2013) menyebutkan bahwa penyerbukan silang buatan pada cabai umumnya masih mudah dilakukan jika masih dalam satu spesies. Namun, jika penyerbukan silang dilakukan antar spesies cabai, maka umumnya persilangan akan mengalami hambatan. Hambatan yang sering terjadi diantaranya adalah sulitnya tejadi fertilisasi, atau jika fertilisasi berhasil maka tanaman tersebut akan steril. Emboden (1964) melaporkan bahwa persilangan buatan antara $C$. frutescens $\times$ C. baccatum dan C. ChinensexC.baccatum tidak dapat menghasilkan biji.

\section{KESIMPULAN}

Kombinasi tetua memiliki interaksi dengan waktu persilangan dalam meningkatkan keberhasilan proses keberhasilan persilangan. Jika tetua betina adalah Sweet Italian, maka waktu persilangannya semakin pagi (suhu rendah) semakin optimal, yakni di antara pukul 04.00-07.00. Untuk persilangan Katokkon×Garda maupun resiproknya, persentase keberhasilan persilangan semakin meningkat jika dilakukan ketika suhu semakin hangat, antara pukul 06.0008.00. Persilangan antara Garda $\times$ Sweet Italian tidak ada yang berhasil, kemungkinan besar disebabkan oleh adanya maternal effect.

\section{UCAPAN TERIMA KASIH}

Terima kasih kepada Kemenristek Dikti yang telah memberikan dana hibah Penelitian Dosen Pemula, sehingga penelitian ini dapat berjalan lancar. Ucapan terima kasih dapat juga disampaikan kepada pihak-pihak yang membantu pelaksanaan penelitian.

\section{DAFTAR PUSTAKA}

Arif B.A., S. Sujiprihati dan M. Syukur. 2012. Pendugaan Parameter Genetik pada Beberapa Persilangan Antara Cabai Besar dan Cabai Keriting. Jurnal Agronomi Indonesia 40(2): 119-124.

Bahar, Y.H. dan W. Nugraheni. 2008. Hasil Survey Produktivitas Hortikultura. http://www.hortikultura.deptan.go.id.

Badan Pusat Statistik [BPS]. 2009. Produksi Sayuran Indonesia Periode 1997-2010. http://www.bp.go.id, diakses 9 Februari 2017.

Badan Pusat Statistik [BPS]. 2011. Luas Panen, Produksi dan Produktivitas Cabai. http://www.bp.go.id, diakses 9 Februari 2017.

Emboden WA. 1964. A preliminary study of crossing relationships of Capsicum baccatum. Butler University Botanical Studies 14(1):1-5.

Geleta, L. F. and M.T. Labuschagne. 2006. Combining ability and heritability for vitamin C and total soluble solids in pepper (Capsicum annuum L). J. Sci. Food Agric. 86: 1317-1320. DOI: https://doi.org/10.1002/jsfa.2494 .

Herison, C., Rustikawati dan Sudarsono. 2001. Studi potensi heterobeltosis pada persilangan beberapa galur cabai merah (Capsicum annuит L). Buletin Agronomi 29(1):23-26.

Kamble, C., R. Mulge and M.B. Madalageri. 2009. Combining ability for earliness and productivity in sweet pepper (Capsicum annuum L.). Karnataka Journal of Agricultural Sciences 22(1): 151-154.

Kirana, R dan E. Sofiari. 2007. Heterosis dan heterobeltosis pada persilangan lima genotipe cabai dengan metode dialel. Jurnal Horticultura 17(2): 111-117. DOI: http://dx.doi.org/10.21082/jhort.v17n2.2007.p\%25p

Marame, F. Dessalegne, L., Finisa and R.L., Sigvald. 2009. Heterosis and heritability in crosses among Asian and Ethiopian parents of hot peppers genotypes. Euphytica 168:235-247. DOI: https://doi.org/10.1007/s10681-009-9912-9.

Nasir, M. 1999. Efek Heterosis dan heterobeltiosis pada tanaman lombok (Capsicum annuum L). Habitat 10(105): 39-43.

Ritonga, A.W. 2013. Penyerbukan Silang Alami Beberapa Genotipe Cabai (Capsicum annuum L.) dan Penentuan Metode Pemuliaannya. Tesis. Institut Pertanian Bogor, Bogor. 
Seneviratne, K.G.S. and K.N. Kannangara. 2004. Heterosis, heterobeltiosis and commercial heterosis for agronomic traits and yield of chili (Capsicum annuum L). Annals of The Sri Lanka Departement of Agriculture 6:195-201.

Sousa, J.A. de. and N.W.R. Maluf. 2003. Diallel Analysis and Estimation of Genetic Parameters of Hot Pepper (Capsicum chinense Jacq). Scientia Agricola 60: 105-113. DOI : https://doi.org/10.1590/S0103-90162003000100016.

Sujiprihati, S., R. Yunianti, M. Syukur dan Undang. 2007. Pendugaan nilai heterosis dan daya gabung beberapa komponen hasil pada persilangan dialel penuh enam genotipe cabai (Capsicum annuum L.). Buletin Agronomi 35: 112-117.

Vavilov, N.I. 1992. Origin and Geography of Cultivated Plants. V.F. Dorofeyev (Ed.), Translated by D. Love. Cambridge University Press, Great Britain. https://books.google.co.id/books?hl=en\&lr=\&id=BqNOAAAAIAAJ\&oi=fnd\&pg=PR11\&ots= xrH7OIrBgs\&sig=I7JIPWI0v8K0QRXvfosegDHc-QU\&redir_esc=y\#v=onepage\&q\&f=false

Zou, X.X., Y.Q. Ma, R.Y. Liu, Z.Q. Zhang, W.C. Cheng, X.Z. Dai, X.F. Li and Q.C. Zhou. 2007. Combining ability analyses of net photosynthesis rate in peppers (Capsicum annuum L). Agric. Sci. In China No 6(2): 159-166. DOI: https://doi.org/ 10.1016/S1671-2927(07)60030-3. 